\title{
Estratégias de prevenção de acidentes para alunos do ensino fundamental no ambiente escolar: revisão integrativa
}

\author{
Bruna Melo de Oliveira \\ Acadêmica de Medicina, Faculdade de Medicina, Universidade Federal de Alfenas - UNIFAL-MG \\ $\triangle \underline{\text { bruna.bmo.19@gmail.com }}$ \\ Larissa Becker de Godoy \\ Acadêmica de Enfermagem, Escola de Enfermagem, Universidade Federal de Alfenas - UNIFAL-MG
}

\section{Sofia Mello Morais}

Acadêmica de Enfermagem, Escola de Enfermagem, Universidade Federal de Alfenas - UNIFAL-MG

Roberta Garcia Gomes

Enfermeira, Mestra em Enfermagem, Técnica-administrativa em Educação, Universidade Federal de Alfenas UNIFAL-MG

\section{Rogério Silva Lima}

Enfermeiro, Doutor em Ciências pela Escola de Enfermagem de Ribeirão Preto, Professor Adjunto da Universidade Federal de Alfenas - UNIFAL-MG

\section{Resumo:}

O ambiente escolar é um local propício aos acidentes, haja vista que as crianças e adolescentes, por suas características, possueminteresse em explorar novas situações e, nesta fase do desenvolvimento de suas habilidades, estabelecem interações que podem ocasionar acidentes. Para evitá-los, faz-se necessário a aplicação de estratégias efetivas de prevenção. À vista disso, este estudo visa identificar, na literatura, as estratégias de prevenção de acidentes para estudantes do ensino fundamental desenvolvidas emambiente escolar. Trata-se de revisão integrativa da literatura combusca embases de dados eletrônicas. Foram incluídos dez artigos na amostra final. Observou-se que a maioria dos estudos reportou estratégias educativas, tais como, cursos ou aulas sobre prevenção de acidentes, esporádicos ou no contexto de programa de inserção curricular, com o uso de recursos como estruturas ósseas; visita à unidade de emergência; terapia com cães; educação interpares; programa de computador; histórias infantis; atividades lúdicas e pôsteres. Apenas uma produção reportou estratégia de prevenção voltada à segurança no playground.Conclui-se que existempoucos estudos, em sua maioria, de autoria e veiculação internacional, o que pode não corresponder à realidade brasileira. Sugere-se outras pesquisas com vistas à proposição de medidas e avaliação de estratégias no ambiente escolar para prevenção de acidentes no contexto nacional.

Palavras-chave: Acidentes, Prevenção, Ensino Fundamental, Assistência Integral à Saúde.

\section{Accident prevention strategies for elementary school students in the school environment: integrative review}

\begin{abstract}
:
The school environment is a place conducive to accidents, given that children and adolescents, due to their characteristics, are interested in exploring new situations and, at this stage of their skills development, establish interactions that can cause ac cidents. To avoid them, it is necessary to apply
\end{abstract}


effective prevention strategies. In view of this, this study aimed to identify, in the literature, accident prevention strategies for elementary school students developed in a school environment. This is an integrative literature review with search in electronic databases. Ten articles were included in the final sample. Most studies reported educational strategies, such as courses or classes about accident prevention, sporadic or in the context of curriculum insertion program, using resources such as bone structures; visit to the emergency unit; therapy dogs; peer education; computer program; children's stories; playful activities and posters. Only one production reported a safety prevention strategy on the playground. It is concluded that there are few studies, mostly of international authorship and publication, which may not correspond to the Brazilian reality. Further research is suggested witha view to proposing measures and evaluating strategies in the school environment for accident prevention in the national context.

Keywords: Accident, Accident Prevention, Elementary school, Comprehensive Health Care.

\section{Estrategias de prevención de accidentes para estudiantes de primaria en el entorno escolar: revisión integradora}

\section{Resumen:}

El ambiente escolar es un lugar propicio para los accidentes, dado que los niños y adolescentes,debido a sus características, están interesados en explorar nuevas situaciones y, en esta etapa del desarrollo de sus habilidades, establecer interacciones que pueden causar accidentes. Para evitarlos, esnecesario aplicar estrategias de prevención efectivas. A la vista de ello, este estudio busca identificar en la literatura las estrategias de prevención de accidentes con estudiantes de la enseñanza fundamental desarrolladas en ambiente escolar. Se trata de una revisión integrativa de la literatura en las bases de datos electrónicas. Diez artículos fueron incluidos en la muestra final. La mayoría de los estudios informaron estrategias educativas, como cursos o clases sobre prevención de accidentes, esporádicas o en el contexto del programa de inserción curricular, utilizando recursos como estructuras óseas; visita a la unidad de emergencia; perros de terapia; educación entre pares; programa de computadora; cuentos infantiles; actividades lúdicas y carteles. Solo una producción informó una estrategia de prevención de seguridad en el patio de recreo. Se concluye que hay pocos estudios, en su mayoría de autoría y publicación internacional, que pueden no corresponder a la realidad brasileña. Se sugiere realizar más investigaciones con el fin de proponer medidas y evaluar estrategias en el entorno escolar para la prevención de accidentes en el contexto nacional.

Palabras clave: Accidentes, Prevención de Accidentes, Educación Primaria y Secundaria,Atención Integral de Salud.

\section{INTRODUÇÃO}

As condições traumáticas representam a principal causa de mortalidade e incapacidade na população pediátrica (IGLESIAS-BOUSAS; GONZÁLEZ, 2017). Dados do Centers for Disease Control and Prevention (CDC) (2017) destacam os acidentes de trânsito, os afogamentos, os envenenamentos, as queimaduras e as asfixias como responsáveis pela maioria das lesões que ocasionam as mortes na população com idade entre um e 14 anos. Observa-se que esses tipos de agravos são previsíveis e passíveis de prevenção (AMERICAN COLLEGE OF SURGEONS, 2018). 
Os acidentes acontecem comumente no ambiente doméstico e nas suas imediações. Porém, o ambiente escolar também é um local propício a essas ocorrências, haja vista que as crianças e adolescentes, por suas características, possuem interesse em explorar novas situações e, nesta fase do desenvolvimento de suas habilidades, estabelecem interações que podem ocasionar acidentes nesses espaços (SILVA, et al., 2017). Assim, não é incomum os professores relatarem situações na escola que resultem em cortes, sangramentos, entorses e fraturas de membros superiores e inferiores (CARMO, et al., 2017).

A escola pode ter locais propensos às quedas, como os muros/cerca de fácil escalada, bueiros e valas abertas, janelas e rampas sem grades ou telas de proteção, escadas sem corrimões e árvores de grande porte (LIBERAL et al., 2005; SILVA, et al., 2017). Até mesmo durante as aulas de Educação Física Escolar (EFE) os estudantes podem sofrer lesões resultantes de práticas esportivas em gramados e quadras (DEL VECCHIO, et al. 2017). Além disso, aspectos relacionados ao entorno da escola também podem favorecer a ocorrência de acidentes, tais como a presença de animais de grande ou pequeno porte, que pode incorrer em acidentes com mordeduras (LIBERAL et al., 2005), e o tráfego na proximidade, que pode predispor os acidentes de trânsito na entrada e saída da escola (ABD EL-SHAFY, et al. 2017).

Nessa direção, o manual de prevenção de acidentes e primeiros socorros nas escolas, formulado pela Secretaria Municipal da Saúde de São Paulo (SP) aponta que, na faixa etária dos seis aos nove anos de idade, os acidentes mais comuns no ambiente escolar são os esportivos, agressões físicas e traumatismo dentário, e dos 10 aos 14 anos são os acidentes de trânsito, os esportivos e os decorrentes de comportamentos de risco, como uso de álcool e drogas, bullying e uso de armas (FRANÇOSO; MALVESTIO, 2007).

Este problemática é relevante pois, de acordo com Fang et al., (2015) os traumas provocam gastos diretos, que incluem despesas com o tratamento, e gastos indiretos que atingem especificamente a família da vítima. Para a escola, os acidentes também geram transtornos, além da perda de horas de aula, uma vez que o professor responsável pelo aluno tem que interromper as atividades para prestar assistência ao aluno acidentado até os responsáveis chegarem (LIBERAL et al., 2005).

Portanto, para evitar acidentes faz-se necessário a aplicação de intervenções que são, por natureza, constituídas por múltiplos componentes (LIBERAL et al., 2005). Desse modo, é preciso reconhecer quais são os métodos empregados para prevenção de traumatismos na 
escola, com o intuito de identificar as estratégias exitosas e assumir a área da prevenção do trauma como de escopo multidisciplinar. Por conseguinte, justifica-se esse estudo tendo em vista que os resultados podem contribuir para instrumentalizar professores, coordenadores pedagógicos, diretores de escola e profissionais da saúde para análise crítica das características da escola que favorecem os acidentes e das possíveis estratégias que podem ser empregadas para sua prevenção.

À vista disso, o objetivo desta investigação é identificar, na literatura, as estratégias de prevenção de acidentes com estudantes do ensino fundamental desenvolvidas em ambiente escolar.

\section{MATERIAL E MÉTODOS}

Trata-se de uma revisão integrativa da literatura, uma abordagem metodológica cujo propósito é revisar métodos, teorias e estudos empíricos sobre um tema em particular. Buscase sintetizar a literatura relativa a determinado fenômeno para extrair as conclusões (BOTELHO; CUNHA; MACEDO, 2011).

Estabeleceu-se a seguinte pergunta norteadora da pesquisa: quais estratégias desenvolvidas no ambiente escolar para a prevenção de acidentes com alunos do ensino fundamental têm sido evidenciadas pela literatura?

Foi realizada a busca nas seguintes bases de dados eletrônicas: Medical Literature Analysis and Retrieval System Online (MEDLINE/PUBMED), Cumulative Index to Nursing and Allied Health Literature (CINAHAL), Literatura Latino-americana e do Caribe em Ciências da Saúde (LILACS) e Web of Science. Para proceder a busca, utilizou-se os Descritores em Ciências da Saúde (DeCS) para a base de dados LILACS, os Medical Subject Headings (MeSH) para a base MEDLINE/PUBMED e as palavras chaves correspondentes para as bases CINAHAL e Web of Science.

Os descritores utilizados foram: Criança (MeSH); Saúde da criança (MeSH); Enfermagem Pediátrica (DeSC); Quedas Acidentais (MeSH, DeSC); Prevenção de Acidentes (MeSH); Ensino Elementar (DeSC); Saúde Escolar (DeSC); Educação em Saúde (DeSC); Serviços de Saúde Escolar (MeSH); Trauma (DeSC); Risco de trauma (DeSC); Feridas e Lesões (MeSH); Segurança da Criança (DeSC); e as palavras-chaves: Crianças; Prevenção; Programas de 
prevenção; Pediatria; Propensão a acidentes; Acidente infantil; Acidentes em alunos do ensino elementar, Programas de saúde na escola; Acidente; Externo; Os cruzamentos foram realizados com descritores ou palavras chave relacionados à população (criança ou escolar) e aqueles relativos ao fenômeno estudado (trauma ou prevenção) e ao contexto do estudo (escola) associados pelo boleano and para se obter um amplo quantitativo de artigos. Adicionalmente, foi também realizada a busca manual nas referências dos artigos.

Foram incluídos artigos em inglês, espanhol e português, disponíveis eletronicamente na íntegra, que apresentassem estratégias de prevenção de acidentes para estudantes do ensino fundamental desenvolvidas na escola. Foram excluídas as produções que não apresentaram como público alvo sujeitos com idade entre seis a 14 anos, em consonância à definição de estudantes do ensino fundamental vigente no país (BRASIL, 2007). Excluiu-se, também, produções que não enfatizavam o ambiente escolar. Não foi adotado um recorte temporal da data de publicação dos artigos.

A coleta dos dados foi realizada pela autora principal, no período de março de 2017 a agosto de 2018. Para a realização da pré-seleção dos artigos, foram analisados os títulos dos trabalhos e os respectivos resumos resultantes da busca inicial, que resultou em 654 artigos. A partir da leitura dos títulos e resumos dos mesmos, foram selecionados para a leitura do texto completo 40 artigos e acrescentados dois por meio da busca manual, totalizando 42 artigos selecionados. Procedeu-se a leitura do texto completo dos 42 artigos, o que resultou na exclusão de 32 artigos por não corresponderem aos critérios da investigação ou por duplicidade das bases.

Foram mantidos os artigos que apresentavam estratégias direcionadas para estudantes com idade entre cinco e sete anos (MCLAUGHLIN; GLANG, 2009; NASCIMENTO; et al., 2013) e entre oito e 16 anos (CAO, et al., 2015) em função de que também incluíam estudantes com a idade estabelecida no protocolo da revisão e apresentavam intervenções relevantes para resposta ao objetivo do estudo.

Ao final, selecionou-se dez artigos que compuseram a amostra final. O processo de seleção dos artigos está descrito na Figura 1. Propôs-se uma análise dos dados descritiva e interpretativa por meio da leitura dos artigos selecionados à luz da literatura correlata. 
Figura 1. Fluxograma da busca, seleção e inclusão dos artigos da revisão, Alfenas, 2019.

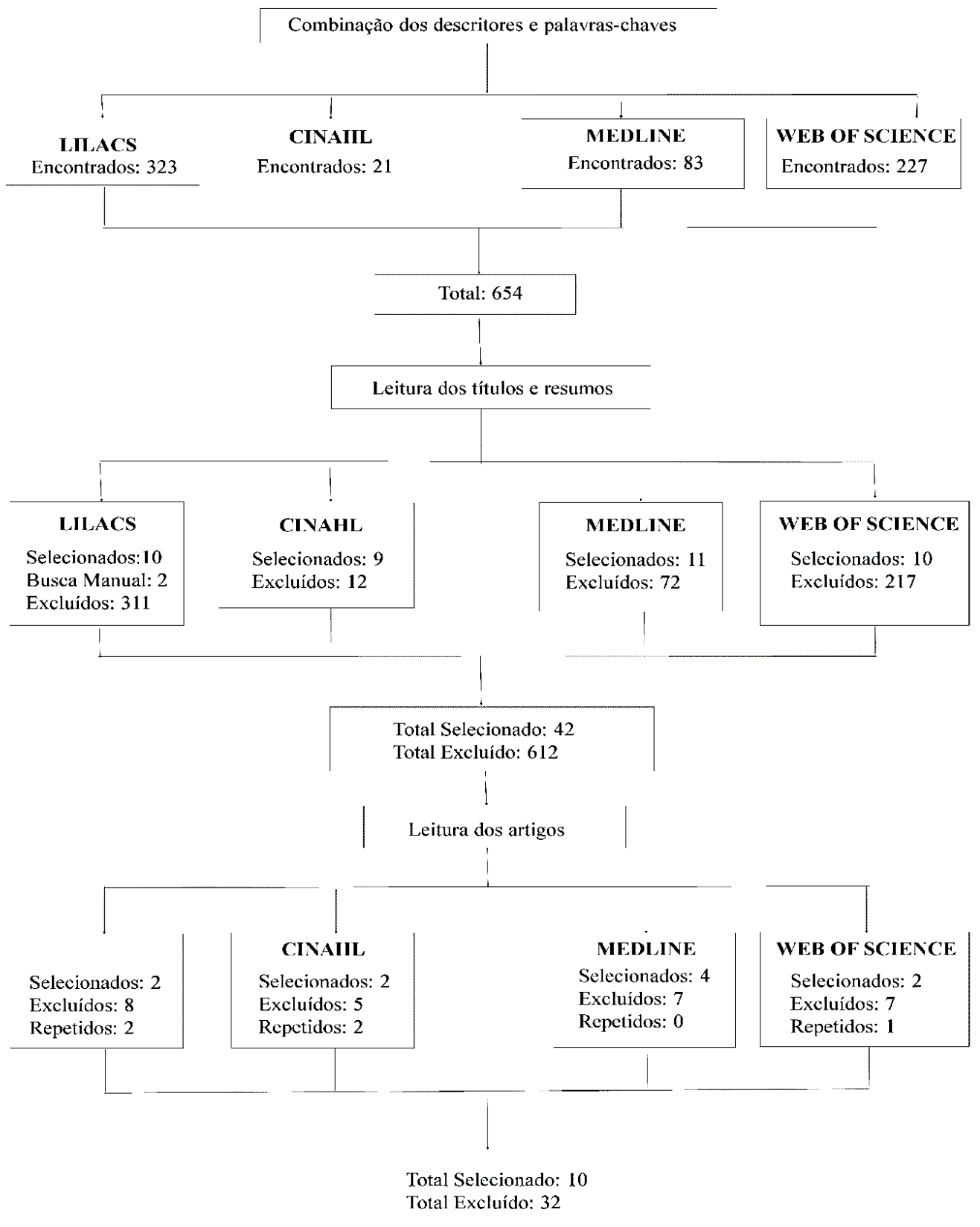

Fonte: elaborado pelos autores, 2018.

\section{RESULTADOS}

A análise dos artigos desta revisão permitiu observar que as questões referentes às estratégias para prevenção de acidentes com escolares são descritas na literatura desde a década de 1990 e 80\% das estratégias foram desenvolvidas ou idealizadas internacionalmente 
(60\% nos EUA, $20 \%$ no Reino Unido e 10\% na China), com apenas $20 \%$ das estratégias desenvolvidas no Brasil.

Dos dez artigos avaliados, quatro não reportavam o número de sujeitos envolvidos no estudo e seis informavam. Desses seis, dois tiveram amostras entre 1900 a 2400 participantes e um teve amostra de 206 alunos.

Quanto ao nível de evidência, proposto por Melnyk e Fineout-overholt (2019), considerando o delineamento reportado pelos autores das pesquisas incluídas na revisão, observou-se que 30 \% dos estudos não são passíveis de classificação por se tratarem de relatos de experiência (ORZEL, 1996; OSLEN; HUDSON; THOMPSON, 2008; PATTERSON, 1999); 30\% são estudos clínicos randomizados, classificados como nível II (CAO, et al. 2015; GRESHAN, et al. 2001; MCLAUGHLIN; GLANG, 2009); 30\% são de delineamento descritivo, classificados como nível III (ESPINDULA; ROCHA; ALVES, 2013; MELLO, et al. 2007; NASCIMENTO, et al. 2013) e um estudo é de nível III, estudo clínico não randomizado (ADAMS; et al. 2014).

Apresenta-se a seguir o quadro com a síntese dos artigos que integraram a revisão.

Quadro 1 - Artigos avaliados segundo ano de publicação, periódico/autor, país, objetivo, método, estratégia aplicada/proposta, população, Alfenas, 2019.

\begin{tabular}{|c|c|c|c|c|c|}
\hline $\begin{array}{l}\text { Periódico/Autor } \\
\text { /Ano }\end{array}$ & País & Objetivo & Método & $\begin{array}{c}\text { Estratégia aplicada } \\
\text { / Proposta }\end{array}$ & População \\
\hline $\begin{array}{l}\text { Accident and } \\
\text { Emergency Nursing } \\
\text { ORZEL, M.N. } \\
1996\end{array}$ & $\begin{array}{l}\text { Reino } \\
\text { Unido }\end{array}$ & $\begin{array}{ll}\text { Descrever } & \text { um } \\
\text { programa } & \text { de } \\
\text { prevenção } & \text { de } \\
\text { acidentes. } & \end{array}$ & $\begin{array}{lr}\text { Apresentação } & \text { de } \\
\text { projeto piloto } & \text { de } \\
\text { programa } & \text { de } \\
\text { prevenção } & \text { de } \\
\text { acidentes } & \text { evitáveis. } \\
\text { Descreve } & \text { três } \\
\text { principais etapas } & \text { do } \\
\text { projeto, s saber: o } \\
\text { curso na escola sobre } \\
\text { prevenção } & \text { de } \\
\text { acidentes; o curso e a } \\
\text { visita ao hospital; } \\
\text { avaliação r } \\
\text { programa. }\end{array}$ & $\begin{array}{l}\text { Um curso sobre } \\
\text { prevenção de acidentes } \\
\text { dividido em } 2 \text { sessões, } \\
\text { uma com professores e } \\
\text { outra com os alunos. } \\
\text { Visita a um hospital } \\
\text { onde para aprendizado } \\
\text { sobre suporte básico de } \\
\text { vida e passeio na parte } \\
\text { de urgência e } \\
\text { emergência do hospital }\end{array}$ & $\begin{array}{l}\text { Crianças com 10-11 } \\
\text { anos }\end{array}$ \\
\hline $\begin{array}{l}\text { Orthopaedic Nursing } \\
\text { PATTERSON, M. M. } \\
1999\end{array}$ & $\begin{array}{l}\text { Estados } \\
\text { Unidos } \\
\text { da } \\
\text { América } \\
\text { (EUA) }\end{array}$ & $\begin{array}{l}\text { Discutir } \\
\text { estratégias de } \\
\text { prevenção } \\
\text { voltadas para a } \\
\text { redução da } \\
\text { gravidade e a } \\
\text { frequência de } \\
\text { traumas e um }\end{array}$ & $\begin{array}{l}\text { Relato de experiência } \\
\text { de enfermeira que } \\
\text { aplicou um programa } \\
\text { desenvolvido pelo } \\
\text { Departamento } \\
\text { Médico da }\end{array}$ & $\begin{array}{l}\text { O programa de } \\
\text { prevenção consistia em } \\
\text { trabalhar em sala de } \\
\text { aula com estruturas } \\
\text { ósseas e desenvolver a } \\
\text { temáticar sobre } \\
\text { acidentes com base nas } \\
\text { vivências dos alunos }\end{array}$ & $\begin{array}{l}\text { Alunos com idade } \\
\text { entre } 6 \text { a } 11 \text { anos }\end{array}$ \\
\hline
\end{tabular}




\begin{tabular}{|c|c|c|c|c|c|}
\hline & & $\begin{array}{l}\text { programa } \\
\text { projetado para } \\
\text { ensinar as } \\
\text { crianças sobre } \\
\text { os ossos do } \\
\text { corpo e como } \\
\text { prevenir lesões } \\
\text { ósseas. }\end{array}$ & $\begin{array}{l}\text { Universidade de } \\
\text { Massachusetts. }\end{array}$ & $\begin{array}{l}\text { para verificar os } \\
\text { conhecimentos sobre } \\
\text { prevenção e introduzir } \\
\text { novos conhecimentos. }\end{array}$ & \\
\hline $\begin{array}{l}\text { Journal of Pediatric } \\
\text { Nursing } \\
\text { GRESHAN, L. S. et al. } \\
2001\end{array}$ & EUA & $\begin{array}{l}\text { Avaliar } \quad \text { o } \\
\text { impacto do } \\
\text { programa } \\
\text { "Think First for } \\
\text { Kids". }\end{array}$ & $\begin{array}{lr}\text { Estudo randomizado } \\
\text { pré-teste e pós-teste. } \\
\text { Sete escolas } & \text { foram } \\
\text { selecionadas } & \text { para } \\
\text { participar } & \text { da } \\
\text { intervenção. } & 1977 \\
\text { escolares } & \\
\text { participaram } & \text { do } \\
\text { estudo. } & \end{array}$ & $\begin{array}{l}\text { Adição no currículo } \\
\text { escolar do método } \\
\text { “ThinkFirst For Kids”, um } \\
\text { programa que facilita a } \\
\text { inserção de aulas sobre } \\
\text { prevenção de acidentes } \\
\text { no currículo, nas grades } \\
\text { de matemática, } \\
\text { literatura ou ciências. }\end{array}$ & $\begin{array}{l}\text { Escolares comidade } \\
\text { entre } 6 \text { a } 9 \text { anos. }\end{array}$ \\
\hline $\begin{array}{l}\text { Journal of Trauma } \\
\text { MELLO, M. J. et al. } \\
2007\end{array}$ & EUA & $\begin{array}{lr}\text { Descrever } & 4 \\
\text { programas de } & \text { drevenção } \\
\text { prentados na } \\
\text { apresentadra } \\
\text { conferência } \\
\text { Injury } \quad \text { Free } \\
\text { Coalation for } \\
\text { Kids. }\end{array}$ & 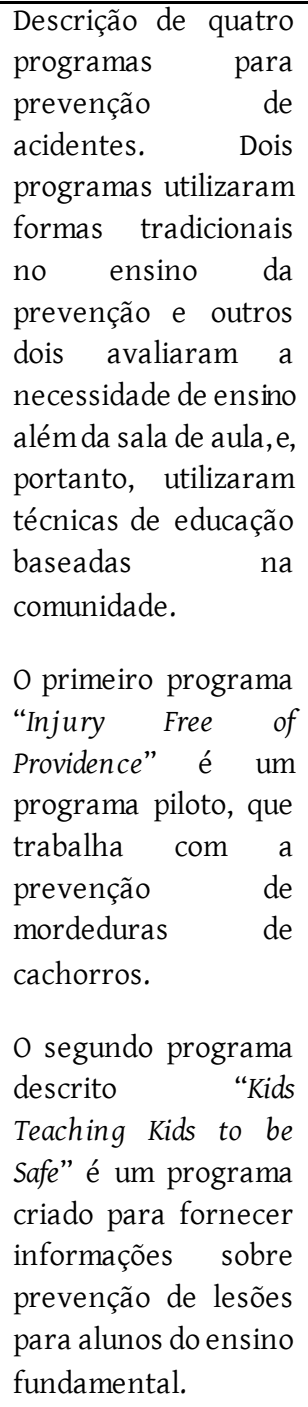 & 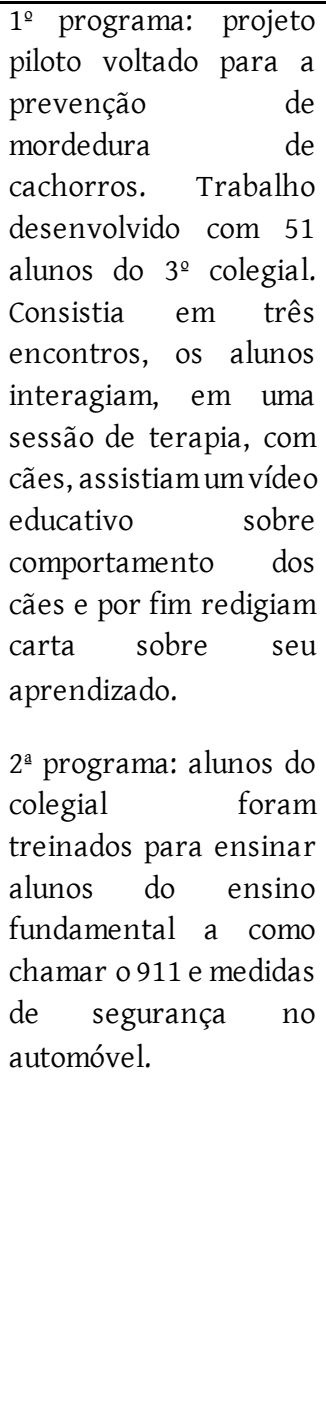 & $\begin{array}{l}1^{\circ} \text { programa alunos } \\
\text { entre } 14 \text { e } 18 \text { anos. } \\
2^{\circ} \text { programa para } \\
\text { alunos de } 15 \text { a } 17 \\
\text { anos e alunos de } 6 \text { a } \\
11 \text { anos }\end{array}$ \\
\hline
\end{tabular}




\begin{tabular}{|c|c|c|c|c|c|}
\hline & & & 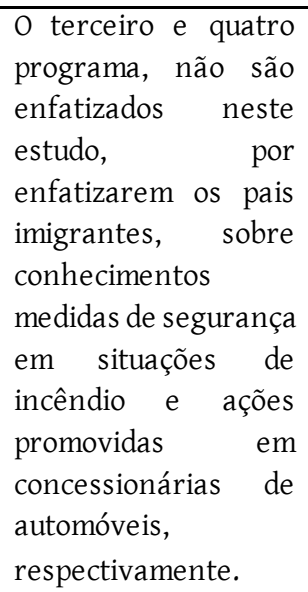 & & \\
\hline $\begin{array}{l}\text { The Journal of School } \\
\text { Nursing } \\
\text { OSLEN, H. M.; } \\
\text { HUDSON, S. D.; } \\
\text { THOMPSON, D. } \\
2008\end{array}$ & $\overline{E U A}$ & \begin{tabular}{l}
\multicolumn{2}{l}{ Prover } \\
informações \\
sobre como \\
desenvolver um \\
plano de \\
prevenção de \\
acidentes em \\
playgrounds de \\
escolas.
\end{tabular} & $\begin{array}{l}\text { Projeto piloto que } \\
\text { ensina como montar, } \\
\text { no ambiente escolar, } \\
\text { um playground } \\
\text { adequado para que as } \\
\text { crianças possam } \\
\text { brincar e desenvolver } \\
\text { suas habilidades sem } \\
\text { correr riscos de se } \\
\text { acidentarem. }\end{array}$ & $\begin{array}{l}\text { Descreve-se } r \text { os } \\
\text { principais problemas } \\
\text { encontrados nos } \\
\text { playgrounds que podem } \\
\text { ocasionar acidentes, em } \\
\text { seguida explica-se como } \\
\text { desenvolver um plano } \\
\text { de prevenção e o que ele } \\
\text { deve conter } \\
\text { (treinamento de } \\
\text { supervisores e crianças, } \\
\text { sistema para relato de } \\
\text { lesões, documentação } \\
\text { sobre os danos). }\end{array}$ & 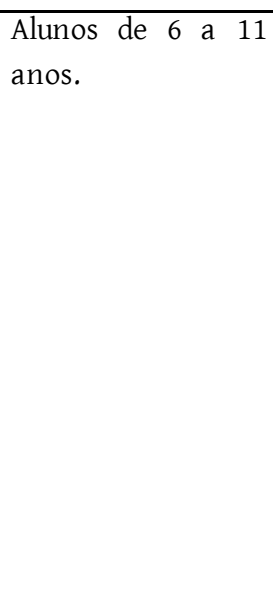 \\
\hline $\begin{array}{l}\text { Journal of Pediatric } \\
\text { Psychology } \\
\text { MCLAUGHLIN, K. A; } \\
\text { GLANG, A } \\
2009\end{array}$ & $\begin{array}{l}\text { Reino } \\
\text { Unido }\end{array}$ & $\begin{array}{lr}\text { Avaliar } & a \\
\text { eficiência } & \text { do } \\
\text { programa } & \text { "Bike } \\
\text { Smart" } & \end{array}$ & $\begin{array}{l}\text { Estudo randomizado } \\
\text { envolvendo } 206 \\
\text { estudante do ensino } \\
\text { fundamental que } \\
\text { foram divididos em } \\
\text { umgrupo controle, no } \\
\text { qual foi aplicado um } \\
\text { projeto de controle } \\
\text { aleatório, e umgrupo } \\
\text { intervenção, no qual } \\
\text { foi aplicado o o } \\
\text { programa "Bike } \\
\text { Smart" e uma } \\
\text { intervenção de como } \\
\text { colocar capacete. }\end{array}$ & $\begin{array}{l}\text { O "Bike Smart" é um } \\
\text { programa } \\
\text { computador } \\
\text { desenvolvido pela } \\
\text { eHealth, que utiliza } \\
\text { vídeos, animações e } \\
\text { imagens para treinar as } \\
\text { crianças a desenvolver } \\
\text { habilidades para andar } \\
\text { de bicicleta de forma } \\
\text { segura. }\end{array}$ & $\begin{array}{l}\text { Crianças entre } 5-7 \\
\text { anos. }\end{array}$ \\
\hline $\begin{array}{l}\text { Rev. Bras. de } \\
\text { Queimaduras } \\
\text { ESPINDULA, A. P; } \\
\text { ROCHA, L.S.M.; } \\
\text { ALVES, M.O. } \\
2013\end{array}$ & Brasil & $\begin{array}{l}\text { Estudo } \\
\text { descritivo que } \\
\text { visa analisar o } \\
\text { perfil de } \\
\text { pacientes } \\
\text { admitidos com } \\
\text { diagnósticos de } \\
\text { queimaduras no } \\
\text { Hospital das } \\
\text { Clínicas (HC) da }\end{array}$ & $\begin{array}{l}\text { Etapa 1: um estudo } \\
\text { descritivo com coleta } \\
\text { de dados secundários } \\
\text { de prontuários } \\
\text { arquivados no Serviço } \\
\text { de Arquivos Médicos } \\
\text { do HC. } \\
\text { Etapa 2: Foi realizada } \\
\text { uma estratégia de }\end{array}$ & $\begin{array}{l}\text { Foi desenvolvida, } \\
\text { primeiramente, uma } \\
\text { história infantil (A festa } \\
\text { na Floresta), onde três } \\
\text { personagens passavam } \\
\text { por situações de riscos. } \\
\text { Emseguida foi feita uma } \\
\text { roda de conversa com } \\
\text { alunos professores e } \\
\text { profissionais, para que }\end{array}$ & $\begin{array}{l}28 \text { escolares com } 8 \\
\text { anos, de uma escola } \\
\text { da rede pública da } \\
\text { cidade de Uberaba - } \\
\text { MG. }\end{array}$ \\
\hline
\end{tabular}




\begin{tabular}{|c|c|c|c|c|c|}
\hline & & \begin{tabular}{lr|}
\multicolumn{3}{l|}{ Universidade } \\
Federal do \\
Triângulo \\
Mineiro (UFTM) \\
e com base \\
nesses dados \\
realizar uma \\
estratégia de \\
prevenção de \\
acidentes que \\
possam resultar \\
em \\
queimaduras.
\end{tabular} & $\begin{array}{l}\text { prevenção e aplicação } \\
\text { de dois questionários, } \\
\text { pré e pós a estratégia. }\end{array}$ & $\begin{array}{l}\text { relatassem situações de } \\
\text { riscos vividas por } \\
\text { conhecidos, sobre a } \\
\text { temática da história. } \\
\text { Para verificar a } \\
\text { efetividade da } \\
\text { estratégia foi aplicado } \\
\text { questionário, pré e pósa } \\
\text { atividade, com quatro } \\
\text { questões que } \\
\text { abordavam atividades } \\
\text { de riscos que poderiam } \\
\text { resultar em } \\
\text { queimaduras. }\end{array}$ & \\
\hline $\begin{array}{l}\text { Journal of Human } \\
\text { Growth and } \\
\text { Development } \\
\text { NASCIMENTO, E. N. } \\
\text { etal. } \\
2013\end{array}$ & Brasil & $\begin{array}{l}\text { estudo } \\
\text { descreve uma } \\
\text { ação } \\
\text { intersetorial de } \\
\text { prevenção de } \\
\text { acidentes } \\
\text { infantis. }\end{array}$ & $\begin{array}{l}\text { Estudo descritivo com } \\
\text { coleta de dados } \\
\text { secundários e estudo } \\
\text { de intervenção. } \\
\text { No estudo descritivo } \\
\text { foi realizado a coleta } \\
\text { de dados em } \\
\text { prontuários de } \\
\text { pacientes com faixa } \\
\text { etária de } 0 \text { a } 19 \text { anos, } \\
\text { com diagnóstico de } \\
\text { queimadura. } \\
\text { O estudo de } \\
\text { intervenção envolveu } \\
\text { crianças com a } \\
\text { mesma faixa etária } \\
\text { média encontrada na } \\
\text { etapa I. }\end{array}$ & $\begin{array}{l}\text { Foi realizada utilizando } \\
\text { um questionário } \\
\text { aplicado à professora } \\
\text { antes e após as } \\
\text { atividades e uma série } \\
\text { de atividades lúdicas } \\
\text { desenvolvidas com os } \\
\text { alunos. As atividades } \\
\text { realizadas com os } \\
\text { alunos aconteceramem } \\
\text { três momentos } \\
\text { distintos, nos quais se } \\
\text { buscou, por meio de } \\
\text { histórias lúdicas, } \\
\text { identificar situações de } \\
\text { risco e vivências dos } \\
\text { alunos, expor } \\
\text { comportamentos de } \\
\text { risco e como preveni-las } \\
\text { e avaliar os resultados } \\
\text { das atividades aplicadas } \\
\text { anteriormente. }\end{array}$ & $\begin{array}{l}30 \text { alunos do Pré II, } \\
\text { com idade entre } \\
\text { cinco e seis anos e a } \\
\text { professora da } \\
\text { turma. }\end{array}$ \\
\hline $\begin{array}{l}\text { Journal of Trauma } \\
\text { Nursing } \\
\text { ADAMS, C. et al. } \\
2014\end{array}$ & EUA & $\begin{array}{lr}\text { Avaliar } & \text { a } \\
\text { efetividade } & \text { do } \\
\text { programa } & \text { de } \\
\text { segurança } & \text { de } \\
\text { uso } & \text { de } \\
\text { capacetes } & \text { em } \\
\text { escolares. } & \end{array}$ & $\begin{array}{l}\text { Estudo não } \\
\text { randomizado comseis } \\
\text { escolas que nunca } \\
\text { tiveram treinamento } \\
\text { em segurança para } \\
\text { uso de capacetes ou } \\
\text { programas de } \\
\text { prevenção de lesões. } \\
\text { Foram aplicados pré e } \\
\text { pós testes e o grupo } \\
\text { foi dividido em duas } \\
\text { escolas para grupo } \\
\text { controle, duas para o } \\
\text { tratamento padrão e } \\
\text { duas para a } \\
\text { intervenção. }\end{array}$ & $\begin{array}{l}\text { Foi administrada uma } \\
\text { aula de } 20 \text { minutos, por } \\
\text { estudantes de } \\
\text { enfermagem, sobre o } \\
\text { uso de capacetes e em } \\
\text { seguida foi dado um } \\
\text { capacete de bicicleta } \\
\text { para cada aluno. }\end{array}$ & $\begin{array}{l}\text { Crianças em idade } \\
\text { escolar }\end{array}$ \\
\hline
\end{tabular}




\begin{tabular}{|c|c|c|c|c|c|}
\hline $\begin{array}{l}\text { International Journal } \\
\text { of Environmental } \\
\text { Research and Public } \\
\text { Health } \\
\text { CAO. B. et al. } \\
2015\end{array}$ & China & $\begin{array}{lr}\text { Avaliar um } \\
\text { modelo de } \\
\text { intervenção } \\
\text { educativa } \\
\text { multi-level, } \\
\text { school-family- } \\
\text { individual, para } \\
\text { avaliar os } \\
\text { conhecimentos } \\
\text { das crianças } \\
\text { sobre lesões } \\
\text { acidentais, } \\
\text { melhorar as } \\
\text { estratégias de } \\
\text { prevenção e } \\
\text { diminuir a } \\
\text { incidência de } \\
\text { acidentes } \\
\text { pediátricos }\end{array}$ & $\begin{array}{lr}\text { Amostragem de } & \text { dé } \\
\text { múltiplos estágios, } \\
\text { estratificada, } \\
\text { agrupada } \\
\text { probabilidade } \\
\text { proporcional ao } \\
\text { tamanho para a } \\
\text { investigação. } 2342 \\
\text { crianças foram } \\
\text { divididas } \\
\text { aleatoriamente em } \\
\text { um grupo } \\
\text { intervenção e grupo } \\
\text { controle. Foi aplicado } \\
\text { um questionário } \\
\text { antes e após a } \\
\text { intervenção. }\end{array}$ & $\begin{array}{l}\text { A estratégia consistia } \\
\text { em apresentar para } \\
\text { escola, família e } \\
\text { indivíduo um pôster } \\
\text { infantil de prevenção de } \\
\text { lesões nas escolas, uma } \\
\text { carta aberta com } \\
\text { instruções de segurança } \\
\text { para pais/ responsáveis } \\
\text { e uma apresentação em } \\
\text { sobre educação em } \\
\text { saúde para as crianças. } \\
\text { As crianças do grupo } \\
\text { controle receberam } \\
\text { apenas um manual de } \\
\text { educação. Após } 16 \\
\text { meses as crianças } \\
\text { responderam um } \\
\text { questionário sobre } \\
\text { lesões acidentais }\end{array}$ & $\begin{array}{l}\text { Escolares entre } 8 \text { e } \\
16 \text { anos }\end{array}$ \\
\hline
\end{tabular}

Fonte: elaborado pelos autores, 2018.

\section{DISCUSSÃO}

A preocupação com o estabelecimento de metodologias para ensinar a prevenção de acidentes às crianças e adolescentes não é recente, como observado pelo ano de publicação dos artigos. Paradoxalmente, há escassez de estudos numérica e qualitativamente, o que coloca em relevo a necessidade de se empreender esforços para qualificar a produção nesta área.

Em relação aos periódicos em que os artigos foram veiculados, observa-se que a maioria é de origem internacional, com sede nos EUA. Este fato coloca em perspectiva a necessidade de se repensar a produção nacional neste campo e considera-se imprescindível a criação e desenvolvimento de programas sistemáticos de prevenção de acidentes com crianças no contexto nacional, tendo como lócus privilegiado o ambiente escolar.

Nota-se que metade dos artigos encontrados na revisão foram publicados em periódicos especializados da área da enfermagem (Accident and Emergency Nursing, Orthopaedic Nursing, Journal of Pediatric Nursing, Journal of School Nursing e Journal of Trauma Nursing). Isso pode traduzir a histórica preocupação deste campo do saber na prevenção de traumas no 
ambiente escolar. Reconhece-se que os enfermeiros são de suma importância dentro da escola, pois, além de incentivar atividades de promoção de saúde, são capacitados para observar a rotina escolar, detectar problemas e propor possíveis soluções (RASCHE; SANTOS, 2013).

Nesta direção, para Rasche e Santos (2013), o enfermeiro ocupa lugar de destaque dentro do ambiente escolar, como agente promotor da saúde. No Brasil, há relatos sobre as atribuições e a especialização em enfermagem escolar já na década de 1930, entretanto, com o passar dos anos e as mudanças nas políticas nacionais, o enfermeiro escolar foi substituído pelo educador sanitário (RASCHE; SANTOS, 2013). No cenário atual, tem-se a presença de profissionais de enfermagem atuando como membros do corpo escolar em algumas instituições particulares. Nas escolas públicas, o acompanhamento das crianças e o desenvolvimento de atividades voltadas para a promoção da saúde devem ser realizados pelo enfermeiro no contexto da equipe de Estratégia Saúde da Família (ESF). Desde o ano de 2007, com a implantação do Decreto no 6.286, estabeleceu-se que compete à equipe de ESF assegurar estratégias para redução da morbimortalidade por acidentes e violência junto à população escolar (BRASIL, 2007).

Não obstante, é preciso que se questione até que ponto as equipes de ESF conseguem estabelecer medidas sistemáticas para prevenção de lesões por causas externas dentro do ambiente escolar. Segundo Couto et al. (2016), as atividades da ESF são alicerçadas em cinco pilares: a avaliação das condições de saúde das crianças, adolescentes e jovens das escolas públicas; promoção da saúde e ações de prevenção de doenças e de agravos à saúde; educação continuada e capacitação dos profissionais da educação, da saúde e de jovens; monitoramento e avaliação da saúde dos estudantes; monitoramento e avaliação do programa. Dessa forma, em razão da amplitude de ações e da grande demanda pela qual as equipes são responsáveis, as ações exclusivamente voltadas à prevenção de acidentes podem não ser priorizadas no ambiente escolar.

Observou-se que as estratégias encontradas na revisão, embora caracterizadas pela diversidade quanto à ênfase, privilegiam o caráter educativo. Apenas uma (10\%) estratégia propõe o desenvolvimento de atividades também fora do ambiente escolar (ORZEL, 1996), 80\% dos artigos abordam estratégias que propõem atividades educativas no ambiente interno da sala de aula (ADAMS; et al. 2014; CAO, et al. 2015; ESPINDULA; ROCHA; ALVES, 2013; GRESHAN, et al. 2001; PATTERSON, 1999; MCLAUGHLIN; GLANG, 2009; MELLO, et al. 2007; NASCIMENTO, 
et al. 2013) e um artigo (10\%) propõe estratégia de prevenção voltada à segurança nos playgrounds (OSLEN; HUDSON; THOMPSON, 2008).

Nenhuma das propostas estudadas envolvia a prevenção secundária, embora um dos estudos ressalte a necessidade dos outros níveis de prevenção na conclusão (GRESHAM, 2001). Considera-se que as ações dedicadas a evitar a ocorrência de agravos à saúde, ou seja, atividades de prevenção primária, são imprescindíveis em se tratando de agravos traumáticos. Sobretudo, porque mais de $80 \%$ dos traumas pediátricos podem ser prevenidos por meio de estratégias simples (AMERICAN COLLEGE OF SURGEONS, 2018). Todavia, é importante que exista também a preocupação com os outros níveis de prevenção, como a prevenção secundária, que busca a detecção inicial do agravo para alcance melhor do prognóstico (TESSER, 2017).

Nesse sentido, no contexto dos acidentes com escolares são também importantes estratégias de prevenção secundária que possam reduzir a gravidade da lesão na ocasião de sua ocorrência, como treinamento de alunos e professores em primeiros socorros e o uso de equipamentos de proteção durante a prática de atividades esportivas (GÖPFERT, et al. 2018; MOTA; ANDRADE, 2015).

Para Silva et al., (2017) as estratégias educativas com professores favorecem com que o grupo esclareça dúvidas e mitigue a insegurança em prestar assistência inadequada com consequente agravamento da condição da vítima. No entanto, reconhece-se que além das intervenções educativas, a prevenção de acidentes e a segurança na escola necessariamente deve considerar a adequação da estrutura física (SILVA, et al. 2017).

Quanto à característica das estratégias empregadas, observou-se que maioria dos estudos incluídos na revisão reportou estratégias educativas com diversos recursos, tais como, cursos ou aulas sobre prevenção de acidentes; programas de inserção curricular de aulas sobre prevenção; metodologias ativas com uso de estruturas ósseas, visita à unidade de emergência, terapia com cães, educação interpares, programa de computador "Bike Smart", histórias infantis, atividades lúdicas e pôsteres.

Embora se tenha evidência de que o uso da educação pode contribuir para prevenção primária de lesões na escola, são necessárias políticas claras que especifiquem os responsáveis pelo oferecimento dessas medidas (GÖPFERT, et al. 2018) Assim, chama-se atenção para o fato de que muitas propostas foram aplicadas no contexto do desenvolvimento de pesquisas, com 
isso, não se pode afirmar que estas estratégias continuaram a ser desenvolvidas em caráter longitudinal.

Nota-se que nenhum trabalho se dedicou a avaliar a relação entre a estratégia de prevenção e a diminuição de acidentes, em um recorte longitudinal. Portanto, a efetividade das propostas encontradas nessa revisão é reportada apenas em relação ao aumento de conhecimento dos participantes após a intervenção.

Como a maioria das propostas enfatizam o aspecto educativo da prevenção, com exceção de um artigo que estabelece como intervenção a adequação de playgrounds (OSLEN; HUDSON; THOMPSON, 2008), ressalta-se a necessidade de estudos, envolvendo medidas de adequação da estrutura física, assim como intervenções com o objetivo de prevenir lesões esportivas, que possibilitem às escolas guias claros de prevenção de lesões decorrentes de traumas com os alunos, haja vista a escassez de evidências (GÖPFERT, et al., 2018).

\section{CONCLUSÃO}

A maioria dos estudos incluídos na revisão reportou estratégias educativas para prevenção de acidentes para alunos do ensino fundamental no ambiente escolar, tais como, cursos ou aulas sobre prevenção de acidentes, esporádicos ou no contexto de programa de inserção curricular, com o uso de recursos como estruturas ósseas; visita à unidade de emergência; terapia com cães; educação interpares; programa de computador; histórias infantis; atividades lúdicas e pôsteres. Encontrou-se apenas uma produção que reportou estratégia de prevenção voltada à segurança no playground. Nota-se que a maioria dos estudos é de autoria e veiculação internacional, e que podem não corresponder à realidade brasileira.

Como limitação desta revisão aponta-se o recorte dos idiomas português, inglês e espanhol e o número restrito de bases de dados pesquisadas, embora se tenha buscado em bases importantes e representativas. Ademais, reconhece-se que a heterogeneidade de definições sobre a faixa etária que corresponde aos alunos escolares pode ser distinta entre diferentes países.

Não obstante, o presente estudo possibilitou uma visão sobre o estado da arte no tocante às estratégias para estudantes do ensino fundamental com vistas à prevenção de 
acidentes na escola, bem como sobre as lacunas neste campo. Sugere-se outras pesquisas com vistas à proposição de medidas e avaliação da efetividade dessas estratégias no ambiente escolar, haja vista a escassez de produções que levem em conta a realidade socioeconômica e educacional do país.

\section{REFERÊNCIAS}

ABD EL-SHAFY, I.; SAVINO, J.; CHRISTOPHERSON, N.; PRINCE, J. Reduction of pediatric pedestrian hazardous road conditions in a school drop-off zone using video review. Journal of Trauma Acute Care Surgery, Hagerstown, v.83, n. 5, p. s227-232, nov. 2017. DOI: 10.1097/TA.0000000000001599. Disponível em: https:/journals.lww.com/jtrauma/FullText/2017/11002/Reduction_of_pediatric_pedestrian_hazardous_road.10.as px\#pdf-link. Acesso em 12 nov. 2019.

ADAMS, C.; DRAKE, C.; DANG, M.; LE-HINDS, N. Optimization of injury prevention outreach for helmet safety. Journal of Trauma Nursing, Philadelphia, v. 21, n. 3, p. 133-138, maio/jun. 2014. DOI: 10.1097/JTN.0000000000000047. Disponível em: https://www.ncbi.nlm.nih.gov/pubmed/24828777. Acesso em: 19 nov. 2018

AMERICAN COLLEGE OF SURGEONS. ATLS: Student Course Manual. Chicago: American College of Surgeons, 2018.

BOTELHO, L.; CUNHA C.; MACEDO M. O método da revisão integrativa nos estudos organizacionais. Gestão e Sociedade, Belo Horizonte, 5, n. 11, p. 121-136, maio/ago. 2011. DOI: https://doi.org/10.21171/ges.v5i11.1220. Disponível em: https://www.gestaoesociedade.org/gestaoesociedade/article/view/1220/906. Acesso em: 17 nov. 2018

BRASIL. Ministério da Educação. Secretaria de Educação Básica. Ensino fundamental de nove anos: ori entações para a inclusão da cria nça de sei s anos de i dade. Brasília: Ministério da Educação, Secretaria de Educação Básica, 2007. Disponível em: http://portal.mec.gov.br/ensino-fundamental-de-nove-anos. Acesso em: 29 maio. 2019

BRASIL. Presidência da República. Lei n. 8.069, de 13 de julho de 1990. Dispõe sobre o Estatuto da Criança e do Adolescente e dá outras providências. Diário Oficial da União, Poder Executivo, Brasília, DF, 1990.

BRASIL. Presidência da República. Decreto n. 6.286, de 5 de dezembro de 2007. Institui o Pro grama Saúde na Escola PSE, e dá outras providências. Diário Oficial da União, Poder Executivo, Brasília, DF, 2007.

CARMO, H. O.; SOUZA, R. C. A., ARAÚJO C. L. O.; FRANCISCO, A. G. Atitudes dos docentes de educação infantil em situação de acidente escolar. Revi sta de enfermagem do Centro-Oeste Mineiro, Divinópolis, v. 7, e.1457. 2017.DOI: 10.19175/recom.v7i0.1457. Disponível em: http://seer.ufsj.edu.br/index.php/recom/article/view/1457/1573. Acesso em: 28 nov. 2019

CAO, B.; SHI, X.; QI, Y.; HUI, Y.; YANG, H.; SHI, S.; LUO, L.; ZHANG, H.; WANG, X.; YANG, Y. Effect of a multi -level education intervention model on knowledge and attitudes of accidental injuries in rural children in zunyi,southwest china. International Journal Envi ronmental Research and Public Health, Basel, v. 12, n. 4, p. 3903-3914.2015. DOI: 10.3390/ijerph120403903. Disponível em: https://www.mdpi.com/1660-4601/12/4/3903?fbclid=IwAR2b-SxTdGRbIm_cnBufMO-LV-ijyEFR541xpN8FOEX_PYSaLBzCVbaQG4. Acesso em: 28 maio 2019.

CENTER FOR CONTROL OF DISEASE CONTROL AND PREVENTION (CDC). Fatal injury data. 2017. Disponível em: https://webappa.cdc.gov/sasweb/ncipc/leadcause.htmlml. Acesso em: 27 nov. 2019. 
COUTO, A. N.; KLEINPAUL, W. V.; BORFE, L.; VARGAS, S. C.; POHL, H. H.; KRUG, S. B. F. O ambiente escolar e as açõesde promoção da saúde. Cinergis: Revista do Departamento de Educação Física e Saúde e do Mestrado em Promoção da Saúde da Universidade de Santa Cruz do Sul, Santa Cruz do Sul, v. 17, n. 4 (Suplemento 1), out./dez. 2016. DOI: http://dx.doi.org/10.17058/cinergis.v17i0.8150. Disponível em: https://online.unisc.br/seer/index.php/cinergis/article/viewFile/8150/5362. Acesso em: 19 nov. 2018.

DEL VECCHIO, B. F.; SEUS, T. L.; DEL VECCHIO, A. H. M.; SILVA, M. C. Frequência de lesões desportivas em aulas de educação física no ensino fundamental em Campinas: estudo observacional retrospectivo. Conexões:EducaçãoFísica, Esporte e Saúde, Campinas, v. 15, n. 1, jan./mar. 2017. DOI: 10.20396/conex.v15i1.8646003. Disponível em: https://www.periodicos.sbu.unicamp.br/ojs/index.php/conexoes/article/view/8646003/16160. Acesso em:06dez. 2019.

ESPINDULA, A.P; ROCHA, L.S.M.; ALVES, M.O. Perfil de pacientes queimados do Hospital de Clínicas: uma propostade intervenção com escolares. Revi sta Brasileira de Queimaduras, Goiânia, v. 12, n. 1, p.16-21. 2013. Disponível em: http://www.rbqueimaduras.com.br/export-pdf/139/v12n1a05.pdf. Acesso em: 19 nov. 2018.

FRANÇOSO, L. A.; MALVESTIO, M. A. Manual de prevenção de acidentes e primeiros socorros nas escolas. Coordenação de Desenvolvimento de Programas e Políticas de Saúde, São Paulo: SMS, 2007. Disponível em: https://www.amavi.org.br/arquivo/colegiados/codime/2016/Primeiros_Socorros_Manual_Prev_Acid_Escolas.pdf. Acesso em: 18 nov. 2016.

FANG, Y;ZHANG, X.; CHEN, W.; LIN, F.; YUAN, M.; GENG, Z.; YU, H.; DAI, L. Epidemiological characteristics andburden of childhood and adolescent injures a survey of elementary and secondary students in Xiamen, China. BMC Public Health, London, v. 15, p. 1-10. abr. 2015. DOI: https://doi.org/10.1186/s12889-015-1726-1. Disponível em: https://bmcpublichealth.biomedcentral.com/track/pdf/10.1186/s12889-015-1726-1. Acesso em: 29 maio 2016.

FONTELLES, M. J. SIMÕES, M. G.; FARIAS, S. H.; FONTELLES, R. G. S. Metodologia da pesquisa científica: diretrizes para a elaboração de um protocolo de pesquisa. Revista Paraense de Medicina, Belém, v. 23, n. 3, 2009. Disponível em: http://bases.bireme.br/cgi-

bin/wxislind.exe/iah/online/?IsisScript=iah/iah.xis\&src=google\&base=LILACS\&lang=p\&nextAction=lnk\&exprSearc h=588477\&indexSearch=ID. Acesso em: 28 nov. 2018

GÖPFERT, A.; VANHOVE, M.; EMOND, A.; MYTTON, J. Prevention of sports injuries in children at school: a systematic review of policies. BMJ Open \& Sport Exerci se Medicine. v. 4, n. 1, e000346, jun. 2018. DOI: 10.1136/bmjsem-20180003 46. eCollection 2018. Disponível em: https://bmjopensem.bmj.com/content/4/1/e000346. Acesso em 24 nov. 2019.

GRESHAM, L. S. ZIRKLE, D. L.; TOLCHIN, S., JONES, C.; MAROUFI, A.; MIRANDA, J. Partnering for injury prevention: evaluation of a curriculum-based intervention program among elementary school children. Journal of Pediatric Nursing, Philadelphia, v. 16, n. 2, p.77-87, abr. 2001.DOI: https://doi.org/10.1053/jpdn.2001.23148. Disponível em: https://www.sciencedirect.com/science/article/pii/s0882596301990785?via\%3Dihub. Acesso em: 17 nov. 2018.

IGLESIAS-BOUSAS, M. I.; GONZALÉZ, A. S. ¿Cómo mejorar la asistencia al trauma pediátrico. Anales de Pediatria, Barcelona, v. 87, n. 6, p.299-300, dez. 2017. DOI: $\underline{\text { https://doi- }}$ org.ez37.periodicos.capes.gov.br/10.1016/j.anpedi.2017.10.010. Disponível em: https://wwwsciencedirect.ez37.periodicos.capes.gov.br/science/article/pii/S1695403317304204?via\%3Dihub.Acessoem:27nov. 2019.

LIBERAL, E. F.; AIRES, R. T.; AIRES, M. T.; OSORIO, A. C. A. Escola Segura. Jornal de Pediatria, Porto Alegre, v. 81, n. 5, p. 155-163, nov. 2005. DOI: http://dx.doi.org/10.1590/S0021-75572005000700005. Disponível em: http://www.jped.com.br/conteudo/05-81-S155/port.pdf. Acesso em: 18 nov. 2016.

MCLAUGHLIN, K. A; GLANG, A. The effectiveness of a bicycle safety program for improving safety-related knowledge and behavior in young elementary students. Journal of Pediatric Psychology, Washington, v. 35, n. 4, p. 343-353, 2009. DOI: 10.1093/jpepsy/jsp076. Disponível em: https://www.ncbi.nlm.nih.gov/pmc/articles/PMC2858437.Acesso em: 17 nov. 2018. 
MELLO, M. J.; GETZ, M.A.; LAPIDUS, G.; MOSS, J.; SOULOS, P. Innovations in injury prevention education. Journal of Trauma, Baltimore, v. 63, suppl. 3, p.57-59. set. 2007. DOI: 10.1097/TA.0b013e31812f5ecd. Disponível em: https://insights.ovid.com/crossref?an=00005373-200709001-00011. Acesso em:17 nov. 2018.

MELNYK, B. M.; FINEOUT-OVERHOLT, E. Evidence-based pratice in nursing and healthcare: a guide to bestpractice. 4. ed. Philadelphia: Wolters Kluers, 2019.

MOTA, L. L.; ANDRADE, S. R. Temas de atenção pré-hospitalar para informação de escolares: a perspectiva dos profissionais do SAMU. Texto \& contexto enfermagem, Florianópolis, v.24, n.1 , p.38-46, 2015. DOI: http://dx.doi.org/10.1590/0104-07072015000500014. Disponível em: http://www.scielo.br/scielo.php?script=sci_arttext\&pid=S010407072015000100038\&lng=en\&nrm=iso. Acessoem:09 nov. 2019.

NASCIMENTO, E. N.; GIMENIZ-PASCHOAL, S. R.; SEB ASTIÃO, L. T.; FERREIRA, N. P. Ações intersetoriais de prevenção de acidentes na educação infantil: opiniões do professor e conhecimentos dos alunos. Journal of HumanGrowthand Development, São Paulo, v. 23, n. 1, p. 99-106, 2013. Disponível em: http://pepsic.bvsalud.org/scielo.php?script=sci_arttext\&pid=S0104 $-12822013000100015 \& \ln g=$ pt\&nrm=iso\&thng=pt. Acesso em: 19 nov. 2018.

ORZEL, M. N. Injury Minimization Programme for Schools. Accident and Emergency Nursing, Oxford, v. 4, n. 3, p.139-144, 1996. Disponível em: https://www.sciencedirect.com/science/article/pii/s0965230296900612.Acessoem: 17 nov. 2018.

OSLEN, H. M.; HUDSON, S. D.; THOMPSON, D. Developing a playground injury prevention plan. The Journal of School Nursing, Thousand Oaks, v. 24, n. 3, p.131-137, 2008. DOI: 10.1622/1059-8405(2008)024[0131:DAPIPP]2.0.CO;2. Disponível em: https://journals.sagepub.com/doi/full/10.1177/1059840532143214?url_ver=Z39.882003\&rfr_id=ori\%3 Arid\%3 Acrossref.org\&rfr_dat=cr_pub\%3Dpubmed. Acesso em: 17 nov. 2018.

PATTERSON, M. M. Prevention: the only cure for pediatric trauma. Orthopaedic Nursing, Philadelphia, v. 18, n. 4, p. 16-20, jul-ago. $1999 . \quad$ Disponível em: https://journals.lww.com/orthopaedicnursing/Abstract/1999/07000/Prevention__The_Only_Cure_for_Pediatric_T rauma.6.aspx. Acesso em: 17 nov. 2018.

RASCHE, A. S.; SANTOS, M. S. S. Enfermagem escolar e sua especialização: uma nova ou antiga atividade. Revista Brasileira de Enfermagem, Brasília, v.66, n.4, p. 607-610, ago. 2013. DOI: http://dx.doi.org/10.1590/S003471672013000400022. Disponível em:http://www.scielo.br/pdf/reben/v66n4/v66n4a22.pdf. Acesso em: 28 nov. 2018.

SILVA, L. G. S.; COSTA, J. B.; FURTADO, L. G. S.; TAVARES, J. B.; COSTA, J. L. D.. Primeiros socorros e prevenção de acidentes no ambiente escolar: intervenção em unidade de ensino. Enfermagem em foco, Brasília, v. 8, n. 3, p. 25-29, nov. 2019. Disponível em: http://revista.cofen.gov.br/index.php/enfermagem/article/view/893/394. Acessoem: 12 out. 2019.

TESSER, C. D. Por que é importante a prevenção quaternária na prevenção? Revi sta de Saúde Públi ca, São Paulo,v.51, n. 116, 2017. DOI: http://dx.doi.org/10.11606/s1518-8787.2017051000041. Disponível em: http://www.scielo.br/scielo.php? script=sci_arttext\&pid=S0034-89102017000100298\&lng=en\&nrm=iso. Acessoem04 dez. 2019.

$(\mathrm{cc}) \mathrm{Br}$

Este trabalho está licenciado com uma Licença Creative Commons - Atribuição 4.0 Internacional. 